\title{
Operational Modal Analysis and the performance assessment of vehicle suspension systems
}

\author{
L. Soria ${ }^{\mathrm{a}, *}$, B. Peeters ${ }^{\mathrm{b}}, \mathrm{J}$, Anthonis $^{\mathrm{b}}$ and H. Van der Auweraer ${ }^{\mathrm{b}}$ \\ ${ }^{a}$ Politecnico di Bari, Dipartimento di Ingegneria Meccanica e Gestionale, Bari, Italy \\ ${ }^{\mathrm{b}}$ LMS International $n v$, Leuven, Belgium
}

\begin{abstract}
Comfort, road holding and safety of passenger cars are mainly influenced by an appropriate design of suspension systems. Improvements of the dynamic behaviour can be achieved by implementing semi-active or active suspension systems. In these cases, the correct design of a well-performing suspension control strategy is of fundamental importance to obtain satisfying results. Operational Modal Analysis allows the experimental structural identification in those that are the real operating conditions: Moving from output-only data, leading to modal models linearised around the more interesting working points and, in the case of controlled systems, providing the needed information for the optimal design and verification of the controller performance. All these characters are needed for the experimental assessment of vehicle suspension systems. In the paper two suspension architectures are considered equipping the same car type. The former is a semi-active commercial system, the latter a novel prototypic active system. For the assessment of suspension performance, two different kinds of tests have been considered, proving ground tests on different road profiles and laboratory four poster rig tests. By OMA-processing the signals acquired in the different testing conditions and by comparing the results, it is shown how this tool can be effectively utilised to verify the operation and the performance of those systems, by only carrying out a simple, cost-effective road test.
\end{abstract}

Keywords: Operational Modal Analysis, vehicle suspension systems, semi-active and active dampers

\section{Introduction}

Vehicle comfort, road holding and safety are strongly related to an appropriate design of suspensions. Semi-active or active suspension types can be implemented instead of the simply passive systems, commonly utilised, to obtain improvements of the vehicle dynamic behaviour. In those cases, the correct design of a well-performing suspension control strategy plays a fundamental role to obtain satisfying results, and, in the case of active systems, also from energy consumption point of view. The not so high overall efficiency of active systems still remains, indeed, one of their main drawbacks [1].

Operational or Output-only Modal Analysis [2,3] allows the experimental identification of structural dynamics models in the actual operating conditions. Strength of this technique is, indeed, that frequently (i) only the response data are measureable and not the actual loadings. Hence, the system identification has to be based on output-only data. Moreover, since all the real systems are to a certain extent non-linear and often also subjected to non-linear constraining conditions, (ii) the modal models obtained under real loadings give a picture of the system once linearised around the more interesting and representative working points. In the case of control systems, at last, (iii) the identification of the real in-operation behaviour is essential in the areas of the optimal design and verification of the controller performance.

*Corresponding author: L. Soria, Politecnico di Bari, Dipartimento di Ingegneria Meccanica e Gestionale, V.le Japigia, 182, 70126, Bari, Italy. E-mail: soria@poliba.it. 
All these characters are needed for the experimental assessment of suspension systems equipping a passenger car. In particular, if the vehicle ride performance has to be assessed, the heave, roll and pitch rigid body motions will have to be investigated. This can be done mainly by performing (i) driving tests in controlled conditions, i.e. proving ground tests on specific road tracks and (ii) laboratory tests in which the input excitation is emulated by a four poster road simulator [4]. A four poster is a test rig basically consisting of four actuators, one for each wheel, able to reproduce, on a car that actually stands still on it at null speed, a running condition on a certain road profile. In the case of race or high performance cars where aerodynamic loads need also to be reproduced, a seven poster rig can be utilised [5].

Advantages of using multi-shaker rigs are that measurements are more repeatable than in the case of road tests, with extremely low level of external noises, and that it is possible to choose several different deterministic or stochastic excitation signals, allowing tests not feasible on road. Although pure or swept sine waveforms or white or pink random sequences do not represent any realistic road condition, they can be effectively utilised to perform input-output modal analysis (EMA), paying particular attention to the assessment of the non-linearities that affect the whole system [6,7]. Moreover the possibility of reproducing on a shaker rig the loads coming from real road tracks driven at certain speeds, allows mainly to perform durability tests for the fatigue assessment of suspension components [8]. The main drawbacks are, of course, availability and overall cost of a lab equipped with those shaker rigs.

With regards to road tests, it has to be stressed that since the external loads acting on the vehicle commonly remain not known (they could be measured only by using expensive transducer-instrumented wheels) EMA cannot be performed.

In this paper the authors suggest an OMA approach to the performance assessment of vehicle suspension systems. To this aim, two Ford S-MAX, two instances of the same type of vehicle, equipped with two different suspension architectures have been tested. The former is a commercial vehicle equipped with a sky-hook semi-active suspension system having three different parameter settings that the driver is able to select, actually modifying the amount of damping in the system: A normal one which is useful in the most common situations and two other ones corresponding the first to a more comfortable behaviour and the second to a stiffer one. The latter is a prototypic vehicle, equipped with a novel sky-hook active suspension system, designed in the framework of a specific research project [9] and implemented on the vehicle removing some components and replacing them with new others. As a consequence, not only the car damping distribution is expected to be different, but, in a certain way, also the mass and the stiffness ones. The suspension behaviour is effectively governed by a controller, which logic depends on several parameters as the car body heave, pitch and roll velocities and the wheel-body relative velocities. The car speed and the steering wheel angular position and velocity are also parameters that the control strategy takes into account, during operation.

On these two cars, two different in-operation types of tests have been performed, (i) proving ground tests on two different road profiles, driving at different car speeds and (ii) laboratory tests performed by using a four poster test rig. On the test rig, the excitation signals sent to the four shakers have been firstly those needed to simulate the same roughness profiles considered in the road test campaigns. Secondly four uncorrelated random signals have been also utilised, to have a useful reference condition in which the basic OMA assumption was verified.

By OMA-processing the acquired signals in the different testing conditions and by comparing the obtained results, it is shown in what follows how this tool can be effectively utilised to verify the operation and the performance of the two considered suspension systems.

OMA, indeed, becomes a useful designing tool in this field, since it can be used to check the actual behaviour of a prototype at an intermediate or final stage of its optimisation process generally referred to as tuning of the suspensions.

\section{Description of the test campaigns}

For both the considered vehicles, the semi-active suspension equipped car and the active suspension equipped one, four poster and proving ground tests have been performed, as said. The test campaign on each car lasted about 
three days. Two different road profiles have been considered for both the test typologies: (i) The Blue-kay track and (ii) the Florida one. The car velocity on the former profile was $60 \mathrm{~km} / \mathrm{h}$, on the latter $80 \mathrm{~km} / \mathrm{h}$. In the case of four poster tests, also random excitation has been considered. In this case four uncorrelated white sequences have been sent to the four hydraulic actuators. Different maximum amplitudes, in terms of shaker displacement have been considered, in particular 1, 3, $5 \mathrm{~mm}$ in the frequency range from 0 to $30 \mathrm{~Hz}$ and $10 \mathrm{~mm}$ in that from 0 to $15 \mathrm{~Hz}$.

The chosen test layout consisted of 31 sensor locations. In each location the three acceleration components have been measured, by using PCB tri-axial piezoelectric accelerometers.

The output signals have been acquired and recorded by using two LMS SCADAS front-ends, connected in master-slave configuration to achieve the needed number of channels and driven by a laptop PC, running the LMS Test. Lab analysis suite. In all the cases, the sampling frequency has been set equal to $1024 \mathrm{~Hz}$.

In Fig. 1, the geometry of the sensor layout is reported. The different names identify the sensor locations, placed on (i) the car body (including those on the susp. dampers, body side), altogether 24 transducers indicated with the suffix "BODY", (ii) the susp. dampers, wheel side, 4 sensors with "FSTR" and "RSTR", (iii) the driver and front passenger seat rails, 2 transducers with "STRL", and (iv) one sensor on the steering wheel, with "STWL".

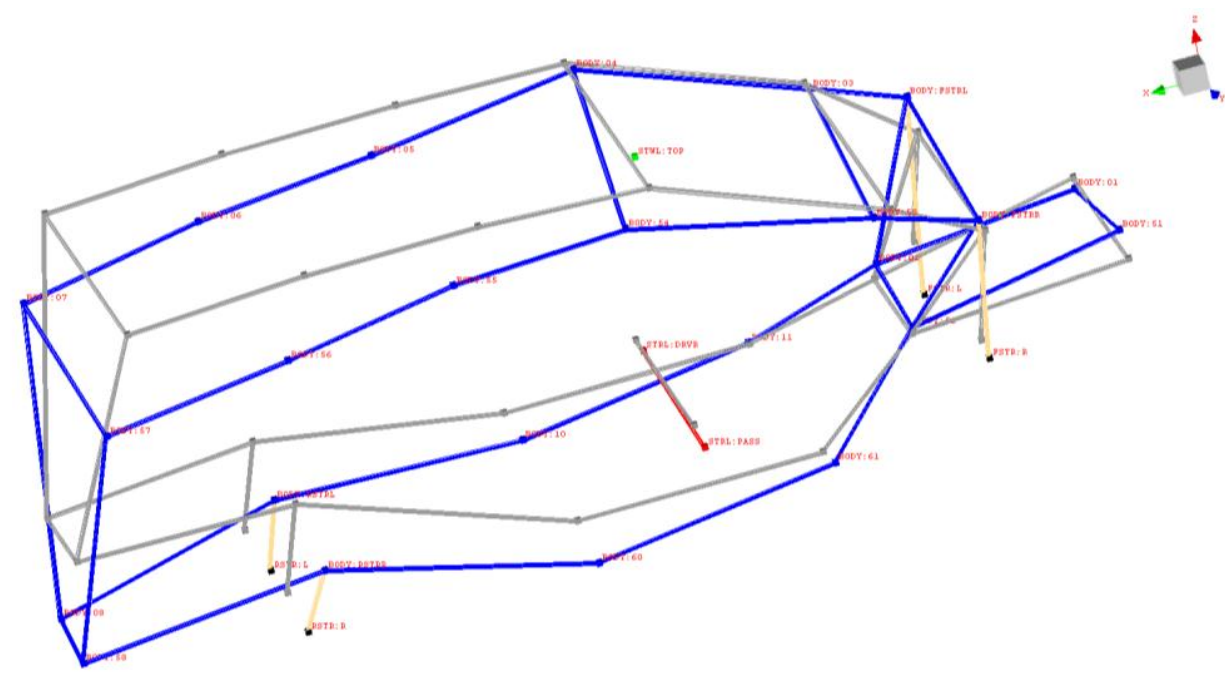

Fig. 1. The car pitch mode: The undeformed model is represented in grey. The set-up geometry with the used 31 sensor locations is highlighted with different names on the deformed model: 24 sensors on the car body, including 4 on the susp. dampers, body side, 4 on the susp. dampers, wheel side, 2 on the rails of the two front seats, 1 on the steering wheel.

In Fig. 2, some images of the tests campaign performed on one of the two cars are reported and, in particular, of the acquisition set-up, showing several sensor locations.

\section{Theoretical background}

\subsection{The road profile excitation}

It is well known that the power spectral density (PSD) of the roughness of a certain road profile is a generally decreasing function of the spatial frequency $k$. In particular, several possible analytical approximations of the PSD function have been proposed and can be found in the technical literature [10], basically obtained by fitting experimental data.

Since the spatial frequency $k$ is the inverse of the wavelength $\lambda$, one has that the time frequency $f=u k$, where $u$ is the car velocity. In Figs $3 a$ and $3 b$ the PSDs of the two road roughness profiles, Blue-kay and Florida, considered 


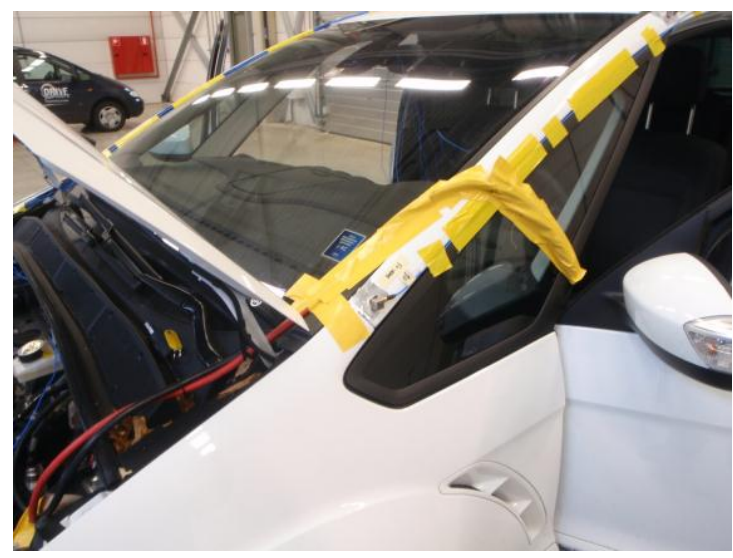

(a)

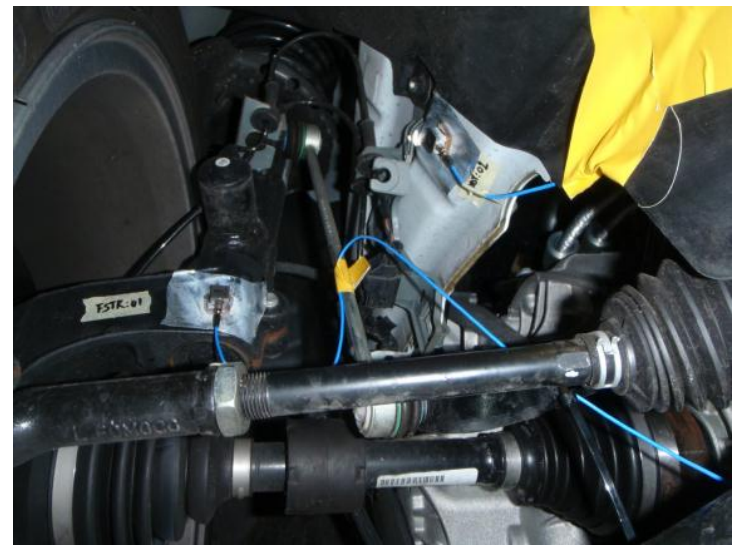

(c)

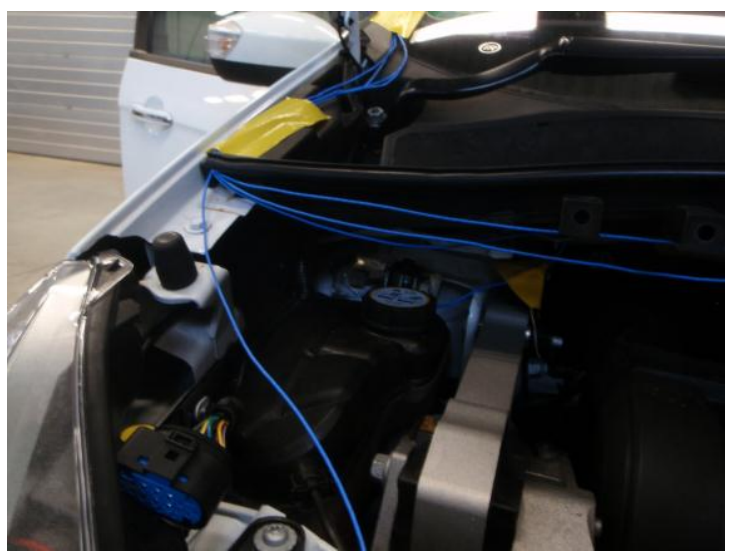

(b)

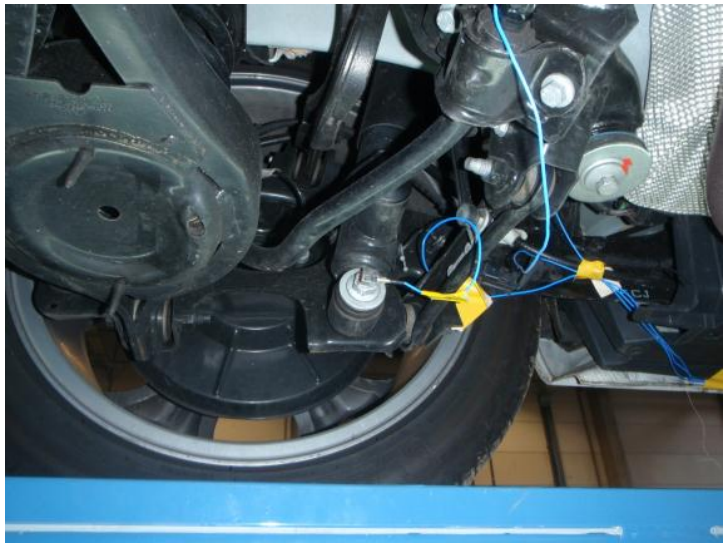

(d)

Fig. 2. The acquisition set-up, some sensor locations: On the car body (a), on the front-right suspension, body side (b), on the front-left and rear-right suspensions, wheel side (c, d).

in the road tests are shown as functions of the time frequency $f$. The car velocity values in the two cases were respectively 60 and $80 \mathrm{~km} / \mathrm{h}$. By simple calculations it is possible to conclude that the wavelength range from 100 to 1 m corresponds to a time frequency range from 0.2 to $20 \mathrm{~Hz}$, which is that normally considered in vehicle dynamics for comfort, safety and road holding analyses and that is usually referred to as ride [11].

As it is possible to see, in this range the PSD function of a road profile decreases. For time frequencies smaller than $0.2 \mathrm{~Hz}$ and, hence, for wavelengths higher than $100 \mathrm{~m}$, the PSD function is quite flat.

From these considerations one can conclude that the road input excitation, on each wheel, is not actually a white noise sequence, as requested by the basic OMA assumption, but something more similar to a Brownian or red noise, whose PSD is inversely proportional to $f^{2}$.

This is still a suitable type of excitation for OMA, since it does not contain peaks in the spectrum that could lead to extra-peaks in the output responses, not related to structural modes.

It has to be moreover said that the input excitation on the front wheels is in a certain way correlated with that on the rear wheels and a correlation might also exist between inputs belonging to the two different sides of the vehicle. This means that the input power spectral density matrix will have some of the off-diagonal terms not null. Even for this reason, the overall input excitation does not strictly respect the basic OMA formulation. However, aim of the analysis reported in the following sections is to show that it is still possible to obtain reliable modal models by processing, with a standard operational modal parameter estimation algorithm, the raw time output data recorded during a road test. 


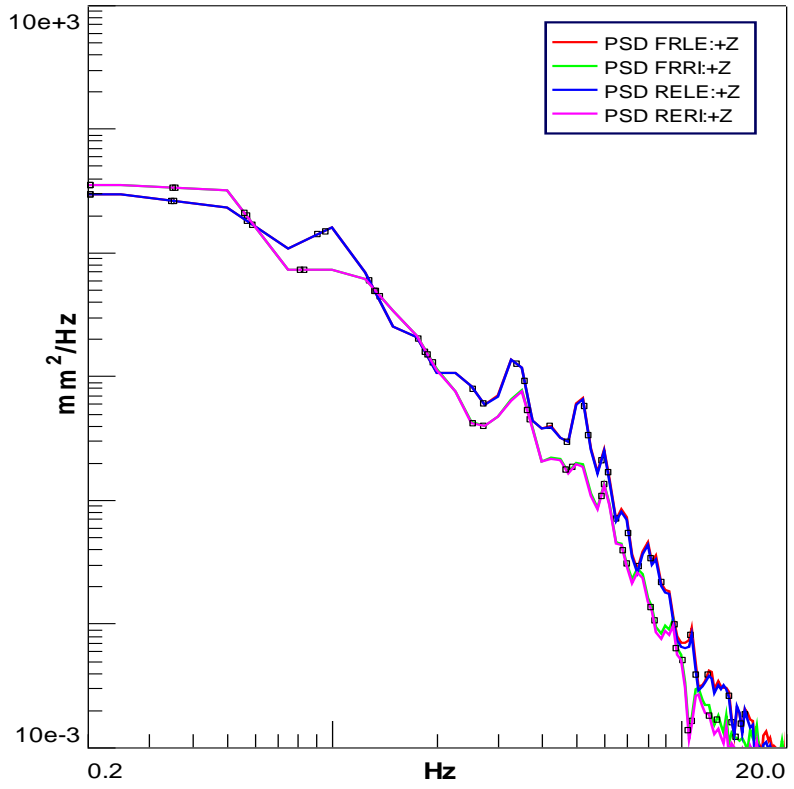

(a)

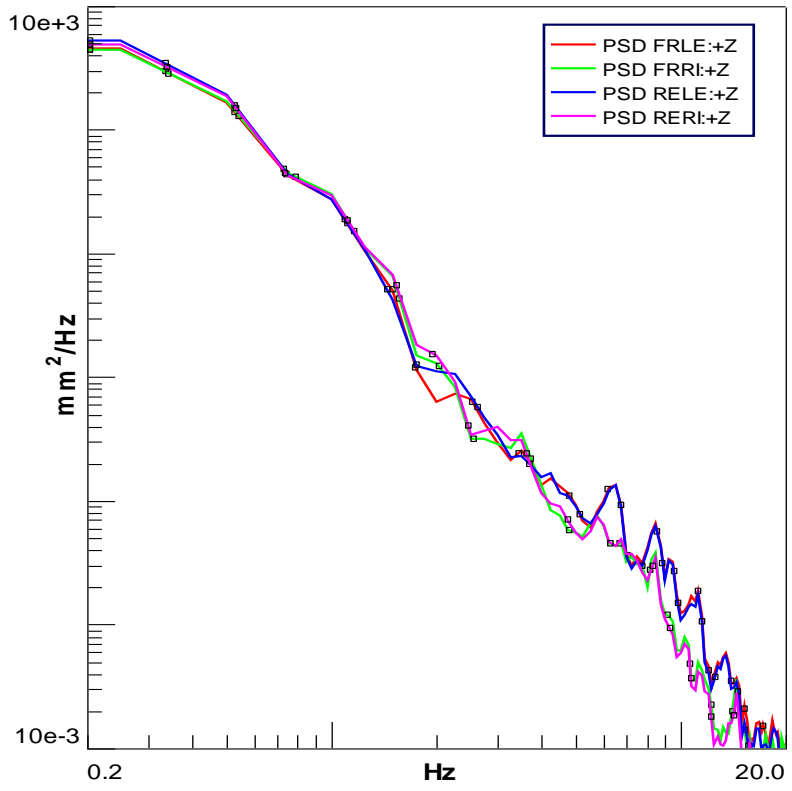

(b)

Fig. 3. The road profile roughness PSD of (a) the Blue-kay track $(60 \mathrm{~km} / \mathrm{h})$ and of (b) the Florida track $(80 \mathrm{~km} / \mathrm{h})$.

\subsection{Pre-processing of the operational data and operational modal parameter estimation}

Since most of the output-only modal parameter estimation methods do not directly use the raw acceleration measurements, but rely on reduced data such as cross-correlations and cross-spectra between signals measured simultaneously at different locations, the correlation or covariance matrix $R_{i} \in \mathbb{R}^{l \times l}$, between the measured output signals $y_{m} \in \mathbb{R}^{l}$, with $l$ the number of outputs and $m$ the sample index, has to be firstly estimated, as the quantity

$$
R_{i}=\frac{1}{N} \sum_{m=0}^{N-1} y_{m+i} y_{m}^{T}
$$

where $N$ is the total number of samples and $i$ is the correlation sample index (also referred to as time lag). The fact that the correlations of a structure, excited by white noise, are similar to impulse responses is the basis for the correlation-driven Stochastic Subspace Identification [12].

Frequency-domain OMA methods require output cross-spectra as primary data. Under the assumption of white noise input, the output spectrum matrix can be modally decomposed as [13]

$$
S_{y y}(j \omega)=\sum_{i=1}^{n} \frac{\left\{v_{i}\right\}\left\langle g_{i}\right\rangle}{j \omega-\lambda_{i}}+\frac{\left\{v_{i}^{*}\right\}\left\langle g_{i}^{*}\right\rangle}{j \omega-\lambda_{i}^{*}}+\frac{\left\{g_{i}\right\}\left\langle v_{i}\right\rangle}{-j \omega-\lambda_{i}}+\frac{\left\{g_{i}^{*}\right\}\left\langle v_{i}^{*}\right\rangle}{-j \omega-\lambda_{i}^{*}}
$$

where $n$ is the number of modes, $\left\{v_{i}\right\} \in \mathbb{C}^{l}$ are the mode shapes, $\left\langle g_{i}\right\rangle \in \mathbb{C}^{l}$ are the so-called operational reference factors, which replace the modal participation factors in the case of output-only data and $\lambda_{i}$ are the system poles, occurring in complex-conjugated pairs and related to the eigenfrequencies $\omega_{i}$ and damping ratios $\xi_{i}$ by the relation $\lambda_{i}, \lambda_{i}^{*}=-\xi_{i} \omega_{i} \pm j \omega_{i} \sqrt{1-\xi_{i}^{2}}$. 
The so-called weighted correlogram can be used as non-parametric spectrum estimate, computed as the Discrete Fourier Transform (DFT) of the weighted estimated correlation matrix in Eq. (1)

$$
S_{y y}(j \omega)=\sum_{m=-L}^{L} w_{m} R_{m} e^{-j \omega m \Delta t}
$$

where $L$ is the maximum number of time lags at which the correlations are estimated and $w_{m}$ denotes the used weighting time window. This number is typically much smaller than the number of data samples to avoid the greater statistical variance associated with the higher lags of the correlation estimates. As the correlation samples at negative time lags contain redundant information, it suffices to consider only the positive time lags when computing the spectra, leading to the so-called half spectra

$$
S_{y y}^{+}(j \omega)=\frac{w_{0} R_{0}}{2}+\sum_{m=1}^{L} w_{m} R_{m} e^{-j \omega m \Delta t}
$$

A more traditional non-parametric spectrum estimate is the weighted averaged periodogram (also known as modified Welch's periodogram) [14]. The advantage of the described correlogram approach is that the use of e.g. a Hanning window can be avoided. A Hanning window introduces a bias on the damping estimates. Instead, just like in impact testing, an exponential window can be applied to the correlation functions before computing the DFT, reducing the effect of leakage and the influence of the higher time lags, which have a larger variance. Moreover, the application of an exponential window to correlations is compatible with the modal model and the pole estimates can be corrected. A thorough discussion and a comparison between the correlogram and periodogram estimates can be found in [15].

It is possible to show, then, that the modal decomposition of the $l \times l$ half spectrum matrix of Eq. (4) corresponds to the sum of only the first two terms of the whole expression in Eq. (2)

$$
S_{y y}^{+}(j \omega)=\sum_{i=1}^{n} \frac{\left\{v_{i}\right\}\left\langle g_{i}\right\rangle}{j \omega-\lambda_{i}}+\frac{\left\{v_{i}^{*}\right\}\left\langle g_{i}^{*}\right\rangle}{j \omega-\lambda_{i}^{*}} .
$$

By using an operational modal identification technique, as the recalled output-only data version of the Stochastic Subspace Identification (SSI) in the time or frequency domain [16] or of the Polyreference Least Square Complex Exponential in the time domain or of the PolyMAX in the frequency domain (Polyreference Least Square Complex Frequency Domain) [17,18], it is possible to build up a stabilisation diagram, assuming subsequently an increasing number of poles [19]. The stabilisation diagram gives a strong indication of the number of present physical modes and allows the selection of the best estimates for the corresponding physical poles. The interpretation of the stabilisation diagram yields, indeed, a set of stable poles and, hence, a set of eigenfrequencies and damping ratios and the corresponding operational reference factors.

The mode shapes can be found, at last, by solving in a linear least square sense Eq. (5), rephrased as

$$
S_{y y}^{+}(j \omega)=\frac{L R}{j \omega}+\sum_{i=1}^{n} \frac{\left\{v_{i}\right\}\left\langle g_{i}\right\rangle}{j \omega-\lambda_{i}}+\frac{\left\{v_{i}^{*}\right\}\left\langle g_{i}^{*}\right\rangle}{j \omega-\lambda_{i}^{*}}+j \omega U R
$$

in which all the present terms are $l \times m$ matrices, with $m$ the number of outputs selected as references and, in particular, LR, UR, respectively the lower and upper operational residuals, have been introduced to model the influence of the out-of-band modes in the considered frequency range.

A validation phase has to follow the identification, to evaluate the quality of the estimated modal model, by using validation tools, among which extremely powerful is the Modal Assurance Criterion (MAC) [19].

The MAC can be used to compare different sets of estimated mode shapes or to investigate the validity of the estimated modes belonging to a given set. In this last case it is generally referred to as autoMAC. It is useful to recall that when two estimates of the same physical mode are considered, the corresponding MAC value will approach the unity, because of the orthogonality condition of the mode shapes. The MAC value calculated considering two estimates of two different physical modes will be conversely low. 


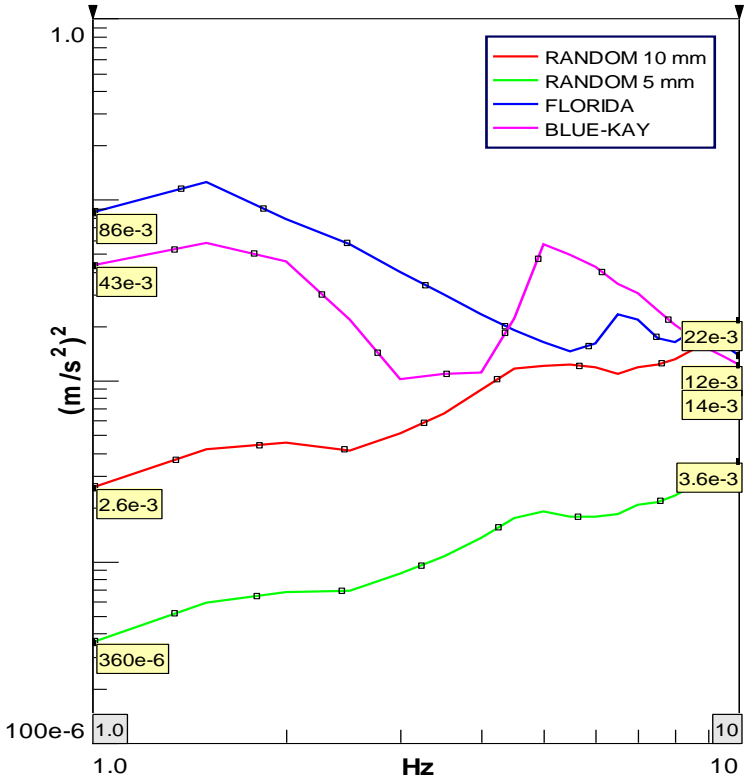

(a)

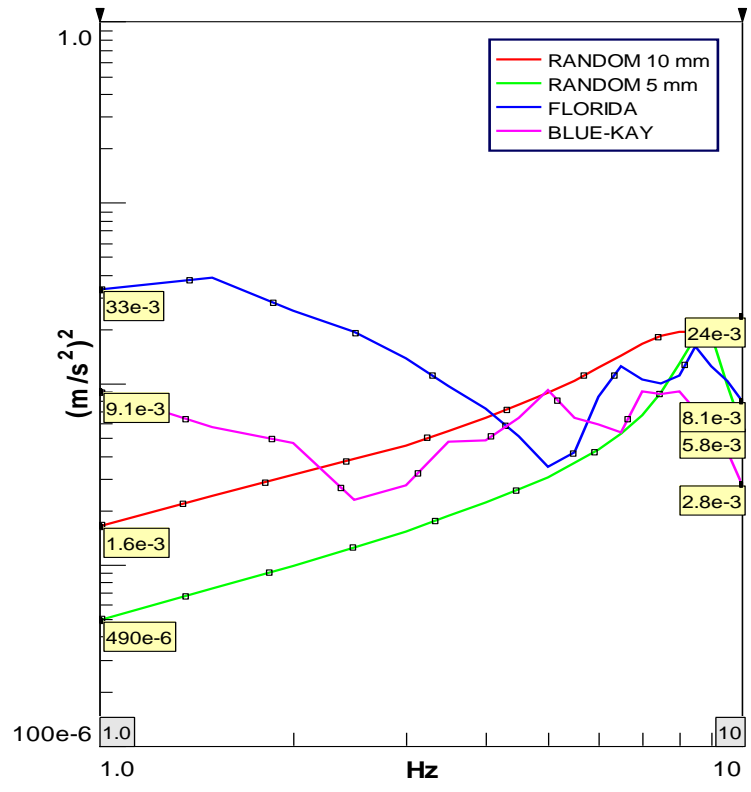

(b)

Fig. 4. Comparison of the driver seat rail output auto-power spectrum in the four poster test cases reported in the legend and for (a) the semi-active suspension equipped car and (b) the active suspension equipped one.

In the following section the results obtained by OMA-processing the time data acquired during the two described test campaigns are discussed. In particular, among the above recalled OMA parameter estimation algorithms the following ones have been chosen, both implemented in the LMS Test.Lab Structure Analysis software: (i) A balanced realisation of SSI in the time domain referred to as Time MDOF [20] and (ii) the PolyMAX technique.

\section{Discussion of the results}

In the above recalled ride frequency range from 0.2 to $20 \mathrm{~Hz}$, it is possible to identify a first sub-range, up to $3 \mathrm{~Hz}$, where the heave, pitch and roll "rigid body" modes have to be found. It is well known that those modes and their eigenfrequencies are mainly related to the stiffness of suspension elastic elements and to the car body geometry and mass distribution. The damping ratios depend of course on damper coefficients.

In the following sections, the suspension operation will be analysed by OMA-estimating the modal parameters in the 0 to $3 \mathrm{~Hz}$ frequency range.

OMA led, of course, also to the identification of higher-frequency deformation modes, more related to the structural response behaviour of the car body itself, that will not be presented in the paper.

In all the cases, the time data have been pre-processed to have the frequency resolution of the estimated output spectra equal to $0.5 \mathrm{~Hz}$. In particular, the previously described correlogram approach has been followed for spectrum estimation, using a maximum number of time lags equal to 2048 and a $10 \%$ exponential window. Regarding processing of the output spectra aimed at modal parameter estimation, for both the utilised identification algorithms, the frequency band used to build up the stabilisation diagrams has been that from 0 to $50 \mathrm{~Hz}$. In the following sections several examples of those obtained diagrams are reported, showing only the interesting portion up to $5 \mathrm{~Hz}$.

It is useful to anticipate that during the random tests performed on the four poster test rig, not enough energy was delivered in the frequency range of interest $(0$ to $3 \mathrm{~Hz})$ with the result that the said searched modes were not excited enough. In Figs 4a and 4b, for both the considered vehicles, a comparison is proposed of the auto-power spectrum of the vertical output signal at the driver seat rail location, during the different four poster tests. As one can clearly see the curves related to random excitation achieve lower values at the lower frequencies. In the case of road input, 
instead, the lower is the frequency, the higher is the energy delivered in the band of interest and, consequently, the better excited are the lower modes. Moreover, the higher are the road profile PSD values and the car velocity, the higher is the excitation level, of course.

In other words, (i) road excitation is naturally suitable to OMA-identify the very low frequency modes of a vehicle and, in particular, since OMA relies only on output responses, (ii) performing simple road tests is the easier and less expensive solution to reach this goal. Moreover, (iii) the obtained modal model already takes into accounts non-linearities, since it represents the linear approximation to the system response at that given working condition. On the other hand, (iv) if a multi-shaker rig is available and, e.g., a random type excitation has to be used, comparable excitation levels in the frequency band of interest will be needed to get useful results by means of OMA. Of course in this case, since shaker inputs can be measured, it is natural to identify the system response by EMA. But, again, the knowledge of the excitation levels in the most representative system operation conditions is even important to estimate correctly the input-output frequency response functions, taking in the right account the non-linear behaviour of the system.

\subsection{The car equipped with semi-active suspensions}

In this section the results obtained in the case of the vehicle equipped with the commercial semi-active suspension system (in "normal" configuration) are commented.

In Table 1, the modal parameters estimated by OMA-processing the data acquired during the four poster tests (4P) performed on this car are collected. In particular, Time MDOF has been used to process all the data sets. As it is possible to see, besides what anticipated regarding random excitation (with which, however, at least the roll has been identified), the results obtained in the case of the two road tracks (reproduced on the test rig) are in good agreement. In Figs 5a and 5b and in Figs $6 \mathrm{c}$ and $6 \mathrm{~d}$ the stabilisation diagram and the autoMAC table respectively had in the Blue-kay case and in the Florida one are reported. The autoMAC values obtained in each of the two cases allow to conclude that the identified mode sets can be considered autonomously validated. In other words, the three modes belonging to each set are satisfactorily independent one from the others, actually representing three different physical modes of the system. To check, than, if the three modes in each set represent different estimates of the same physical modes, the MAC between the two sets has been evaluated and results are reported in Figs 5c (matrix) and $5 \mathrm{~d}$ (table). The comparison confirms the validity of each of the two identified set of mode shapes. Both the road profile cases, Florida and Blue-kay, have been afterwards analysed by means of PolyMAX: In particular, Figs 6a and $6 \mathrm{~b}$ show stabilisation diagram and autoMAC in the Florida case and the MAC between the two Florida mode sets estimated by both the identification techniques is reported in Figs 6e (matrix) and $6 \mathrm{f}$ (table). Even this comparison validates the Florida-PolyMAX mode set as a third estimate of the same set of independent physical modes of the system.

Table 1

Semi-active suspension car: Comparison of modal parameters estimated in different four poster tests (random excitation utilised led to the identification of only one mode in the frequency range from 0 to $3 \mathrm{~Hz}$ )

\begin{tabular}{|c|c|c|c|c|c|c|}
\hline \multirow{2}{*}{$\begin{array}{c}\text { 4P mode } \\
\text { time MDOF }\end{array}$} & \multicolumn{3}{|c|}{ Eigenfrequency [Hz] } & \multicolumn{3}{|c|}{ Damping ratio [\%] } \\
\hline & $5 \mathrm{~mm}$ random & Blue-kay & Florida & $5 \mathrm{~mm}$ random & Blue-kay & Florida \\
\hline 1st (heave) & - & 1.10 & 1.29 & - & 13.4 & 17.0 \\
\hline 2nd (roll) & 1.86 & 1.58 & 1.82 & 14.8 & 7.86 & 7.60 \\
\hline 3rd (pitch) & - & 2.30 & 2.09 & - & 10.7 & 7.63 \\
\hline
\end{tabular}

In Table 2 are, then, collected the modal parameters estimated by OMA-processing the data coming from the proving ground tests (PG), performed on the same car. Again a good agreement has been reached, not only between results come from proving ground tests performed on the two different roads, as shown in Fig. 7, but also between results had from proving ground and four poster tests, as shown in Fig. 8. In particular, in Figs 7a and 7b and in Figs $7 \mathrm{c}$ and $7 \mathrm{~d}$ the stabilisation diagram and the autoMAC respectively had in the Blue-kay case and in the Florida one are reported. Both the analyses have been performed by using PolyMAX. In Figs $7 \mathrm{e}$ and $7 \mathrm{f}$ one can find the 


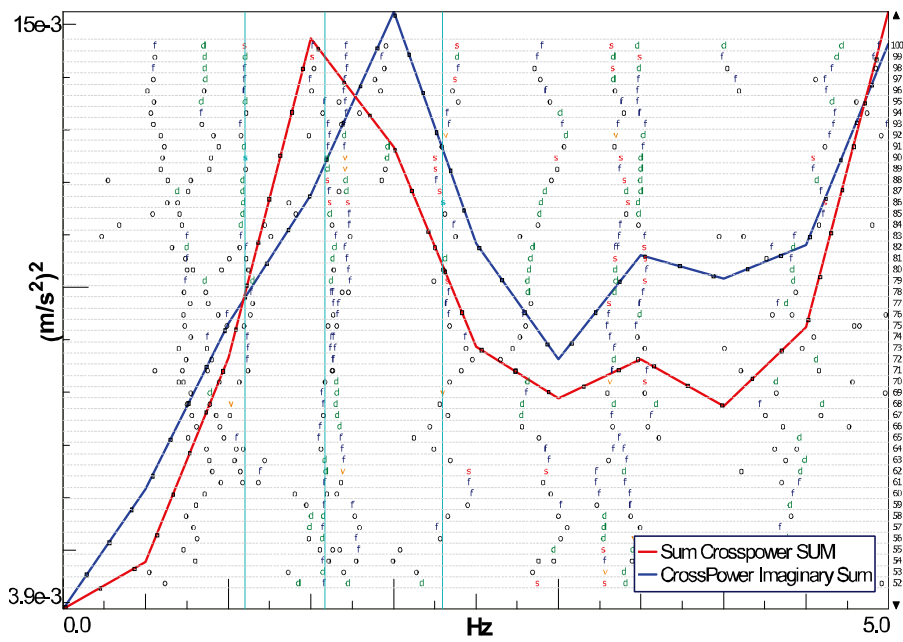

(a)

\begin{tabular}{c|c|c|c|}
$\begin{array}{c}\text { 4P mode } \\
\text { Blue-kay } \\
\text { TMDOF }\end{array}$ & $1^{\text {st }}$ & $2^{\text {nd }}$ & $3^{\text {rd }}$ \\
\hline $\begin{array}{c}1^{\text {st }}(\text { heave }) \\
1.10 \mathrm{~Hz}, \\
13.4 \%\end{array}$ & 100 & 34.7 & 25.7 \\
\hline $\begin{array}{c}2^{\text {nd }}(\text { roll }) \\
1.58 \mathrm{~Hz}, \\
7.86 \%\end{array}$ & 34.7 & 100 & 1.93 \\
\hline $\begin{array}{c}3^{\text {rd }}(\text { pitch }) \\
2.30 \mathrm{~Hz}, \\
10.7 \%\end{array}$ & 25.7 & 1.93 & 100 \\
\hline
\end{tabular}

(b)

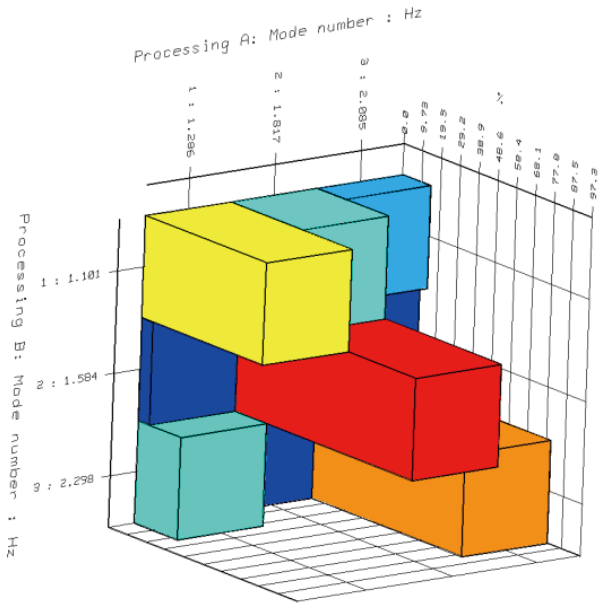

(c)

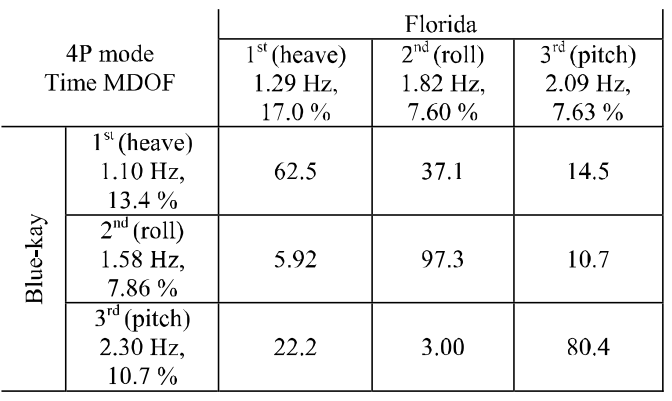

(d)

Fig. 5. Semi-active susp. car, four poster tests: TMDOF stabilisation diagram (a) and autoMAC table (b) in the Blue-kay case. MAC matrix (c) and table (d) between Blue-kay and Florida mode set TMDOF estimates.

Table 2

Semi-active suspension car: Comparison of modal parameters estimated in different proving ground tests

\begin{tabular}{lccccc}
\hline \multirow{2}{*}{$\begin{array}{c}\text { PG mode } \\
\text { PolyMAX }\end{array}$} & \multicolumn{2}{c}{ Eigenfrequency [Hz] } & & \multicolumn{2}{c}{ Damping ratio [\%] } \\
\cline { 2 - 3 } \cline { 5 - 6 } & Blue-kay & Florida & & Blue-kay & Florida \\
\hline 1st (heave) & 1.08 & 1.19 & & 7.05 & 15.5 \\
2nd (roll) & 1.46 & 1.55 & & 14.9 & 19.7 \\
3rd (pitch) & 1.77 & 2.16 & & 9.07 & 20.6 \\
\hline
\end{tabular}

MAC between the two mode sets. In Figs $8 \mathrm{a}$ and $8 \mathrm{~b}$ and in Figs $8 \mathrm{c}$ and $8 \mathrm{~d}$ the MAC respectively between Blue-kay-PG and Florida-4P and Florida-PG and Florida-4P are represented, having all these analyses been performed by using PolyMAX. In all the cases, the validation phase confirmed as reliable the identified mode set estimates. 


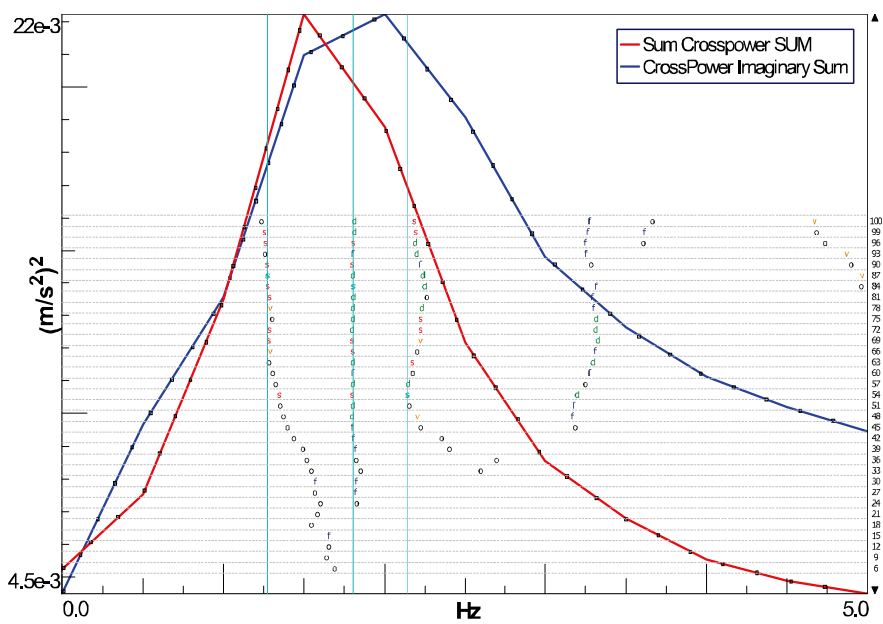

(a)

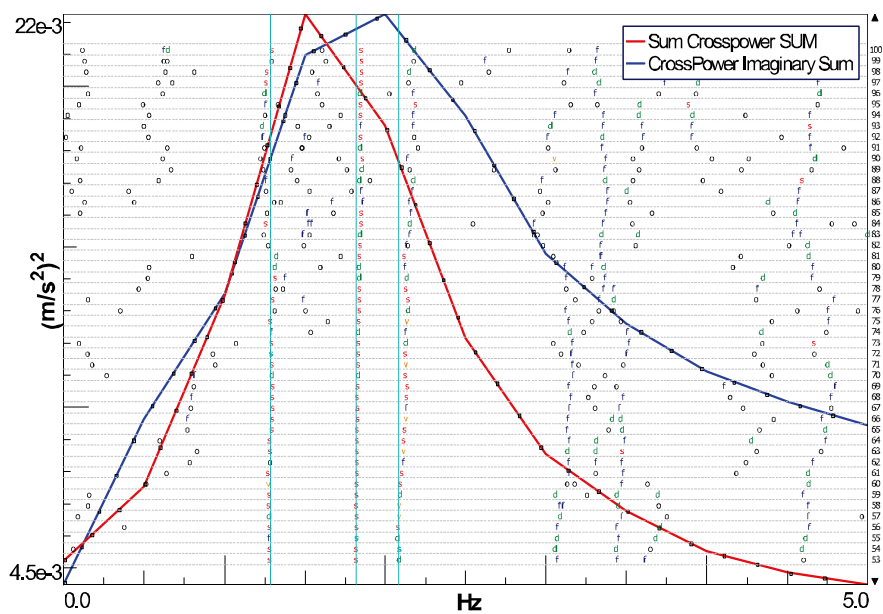

(c)

\begin{tabular}{c|c|c|c}
$\begin{array}{c}\text { 4P mode } \\
\text { Florida } \\
\text { PolyMAX }\end{array}$ & $1^{\text {st }}$ & $2^{\text {nd }}$ & $3^{\text {rd }}$ \\
\hline $\begin{array}{c}1^{\text {st }}(\text { heave }) \\
1.27 \mathrm{~Hz}, \\
13.7 \%\end{array}$ & 100 & 16.6 & 13.9 \\
\hline $\begin{array}{c}2^{\text {nd }}(\text { roll }) \\
1.80 \mathrm{~Hz}, \\
7.45 \%\end{array}$ & 16.6 & 100 & 6.09 \\
\hline $\begin{array}{c}3^{\text {rd }}(\text { pitch }) \\
2.14 \mathrm{~Hz}, \\
17.4 \%\end{array}$ & 13.9 & 6.09 & 100 \\
\hline
\end{tabular}

(b)

\begin{tabular}{c|c|c|c|}
$\begin{array}{c}\text { 4P mode } \\
\text { Florida } \\
\text { TMDOF }\end{array}$ & $1^{\text {st }}$ & $2^{\text {nd }}$ & $3^{\text {rd }}$ \\
\hline $\begin{array}{c}1^{\text {st }}(\text { heave }) \\
1.29 \mathrm{~Hz}, \\
17.0 \%\end{array}$ & 100 & 13.5 & 36.3 \\
\hline $\begin{array}{c}2^{\text {nd }}(\text { roll }) \\
1.82 \mathrm{~Hz}, \\
7.60 \%\end{array}$ & 13.5 & 100 & 15.3 \\
\hline $\begin{array}{c}3^{\text {rd }}(\text { pitch }) \\
2.09 \mathrm{~Hz}, \\
7.63 \%\end{array}$ & 36.3 & 15.3 & 100 \\
\hline
\end{tabular}

(d)

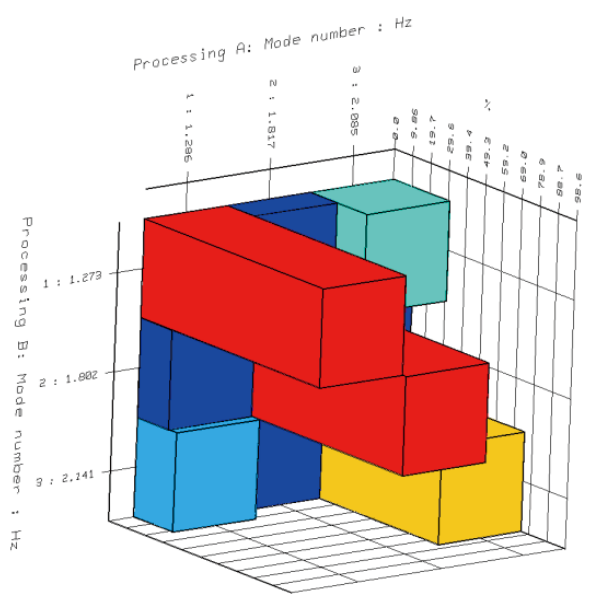

(e)

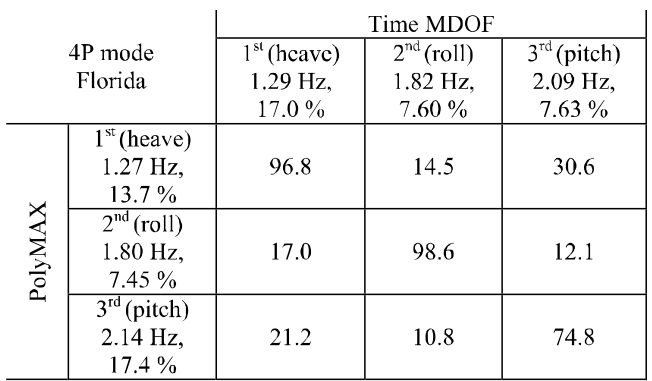

(f)

Fig. 6. Semi-active susp. car, four poster tests: PolyMAX (a) and TMDOF (c) stabilisation diagrams and autoMAC tables (b, d) in the Florida case. MAC matrix (e) and table (f) between these two mode set estimates. 


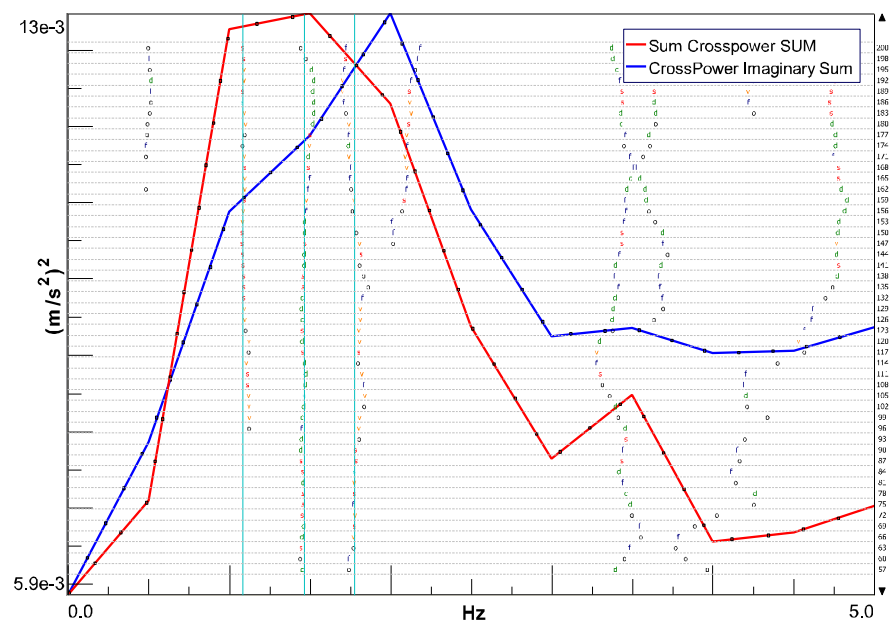

(a)

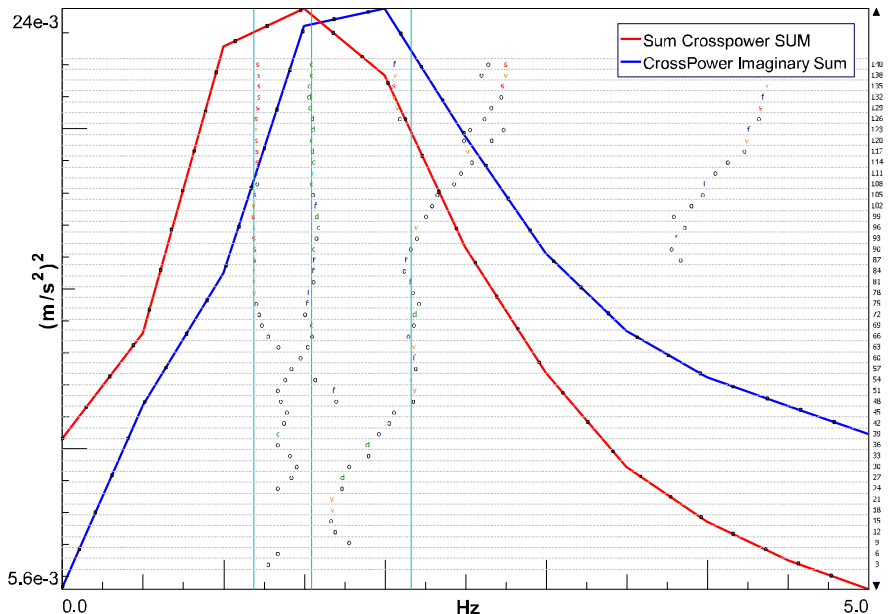

(c)

\begin{tabular}{c|c|c|c|}
$\begin{array}{c}\text { PG mode } \\
\text { Blue-kay } \\
\text { PolyMAX }\end{array}$ & $1^{\text {st }}$ & $2^{\text {nd }}$ & $3^{\text {rd }}$ \\
\hline $\begin{array}{c}1^{\text {st }}(\text { heave }) \\
1.08 \mathrm{~Hz}, \\
7.05 \%\end{array}$ & 100 & 11.1 & 31.6 \\
\hline $\begin{array}{c}2^{\text {nd }}(\text { roll }) \\
1.46 \mathrm{~Hz}, \\
14.9 \%\end{array}$ & 11.1 & 100 & 18.2 \\
\hline $\begin{array}{c}3^{\text {rd }}(\text { pitch }) \\
1.77 \mathrm{~Hz}, \\
9.07 \%\end{array}$ & 31.6 & 18.2 & 100 \\
\hline
\end{tabular}

(b)

\begin{tabular}{c|c|c|c|}
$\begin{array}{c}\text { PG mode } \\
\text { Florida } \\
\text { PolyMAX }\end{array}$ & $1^{\text {st }}$ & $2^{\text {nd }}$ & $3^{\text {rd }}$ \\
\hline $\begin{array}{c}1^{\text {st }}(\text { heave }) \\
1.19 \mathrm{~Hz}, \\
15.5 \%\end{array}$ & 100 & 21.8 & 39.9 \\
\hline $\begin{array}{c}2^{\text {nd }}(\text { roll }) \\
1.55 \mathrm{~Hz},\end{array}$ & 21.8 & 100 & 16.0 \\
$\begin{array}{c}19.7 \% \\
3^{\text {rd }}(\mathrm{pitch}) \\
2.16 \mathrm{~Hz}, \\
20.6 \%\end{array}$ & 39.9 & 16.0 & 100 \\
\hline
\end{tabular}

(d)

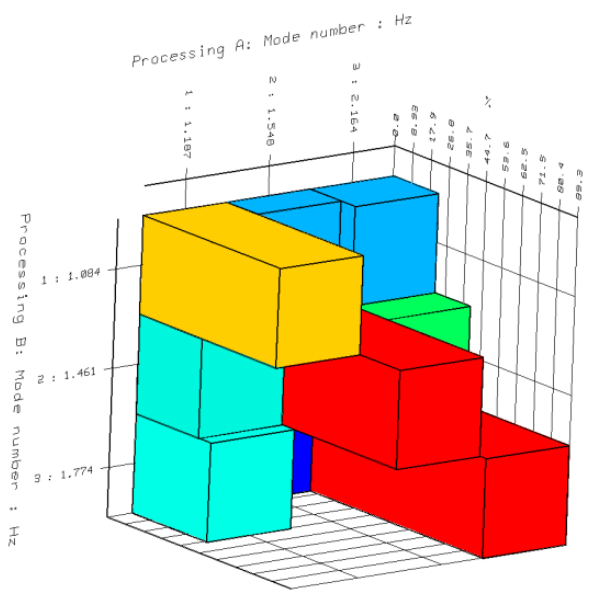

(e)

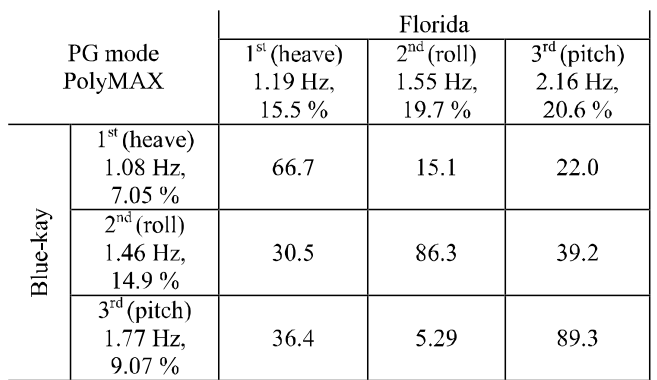

(f)

Fig. 7. Semi-active susp. car, proving ground tests: PolyMAX stabilisation diagrams and autoMAC tables in the Blue-kay (a, b) and Florida (c, d) cases. MAC matrix (e) and table (f) between those two mode set estimates. 


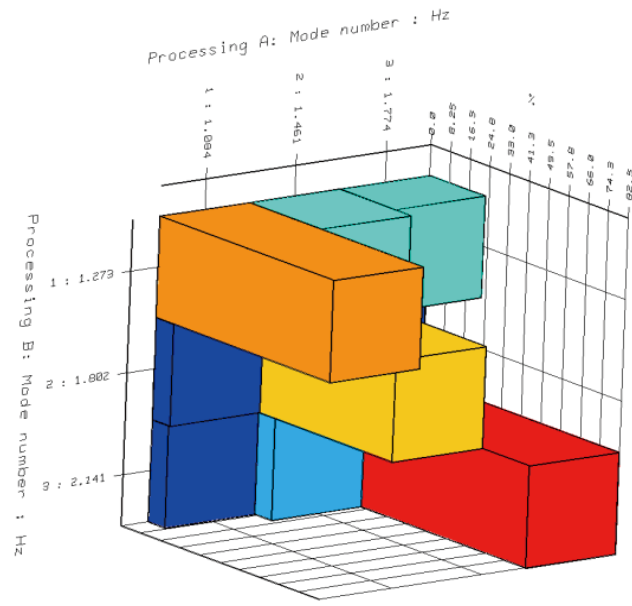

(a)

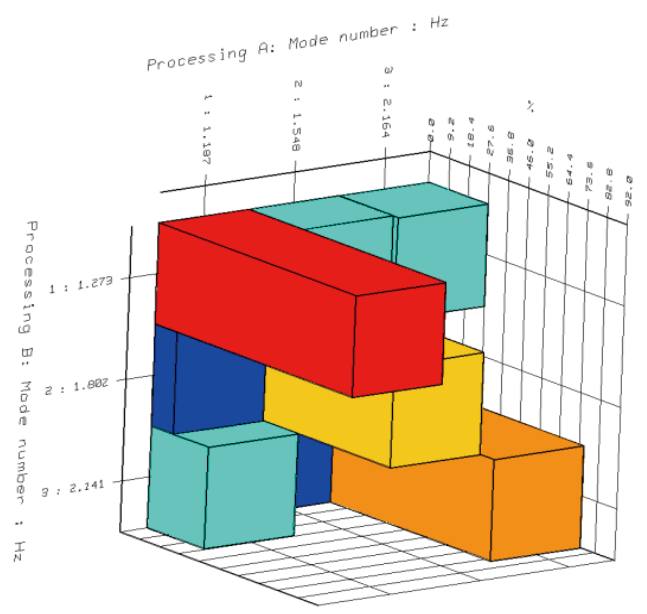

(c)

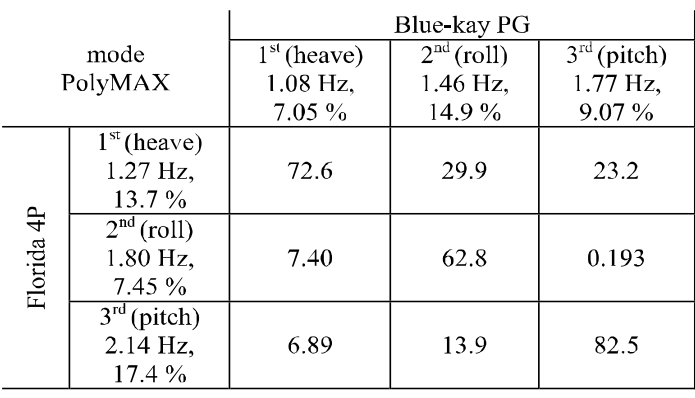

(b)

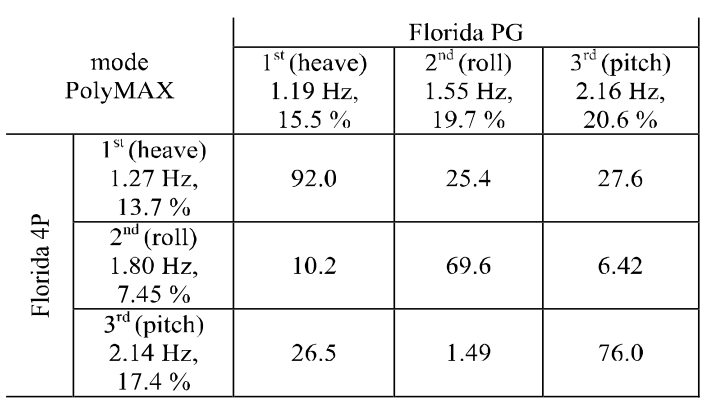

(d)

Fig. 8. Semi-active suspension car: MAC matrix and table in the cases (a, b) Blue-kay, proving ground and Florida, four poster and (c, d) Florida, proving ground and Florida, four poster.

In conclusion, one has had small discrepancies between the eigenfrequencies, with quite well correlated modes and higher discrepancies achieved, in some cases, on damping ratios. Since for a given vehicle, once the rigid body modes have been correctly identified, the suspension operation can be described by studying pole estimates, their quality is a key point, as already in the EMA case. For data sets coming from the same system operating condition, average discrepancies are related to the fact that dissipation is more difficult to be estimated, especially in the case of highly damped systems. The quality of the estimates depends, indeed, on the whole time data processing and, in particular, on the utilised identification techniques. For data sets related to different working points, average discrepancies are moreover related to the suspension operation itself. The excitation level for each mode, at last, has a deep impact on estimates, as stressed above.

\subsection{The car equipped with active suspensions}

In the case of the vehicle equipped with the novel, prototypic suspension system, higher damping values are expected, due to the active operation and performance of the system itself. 


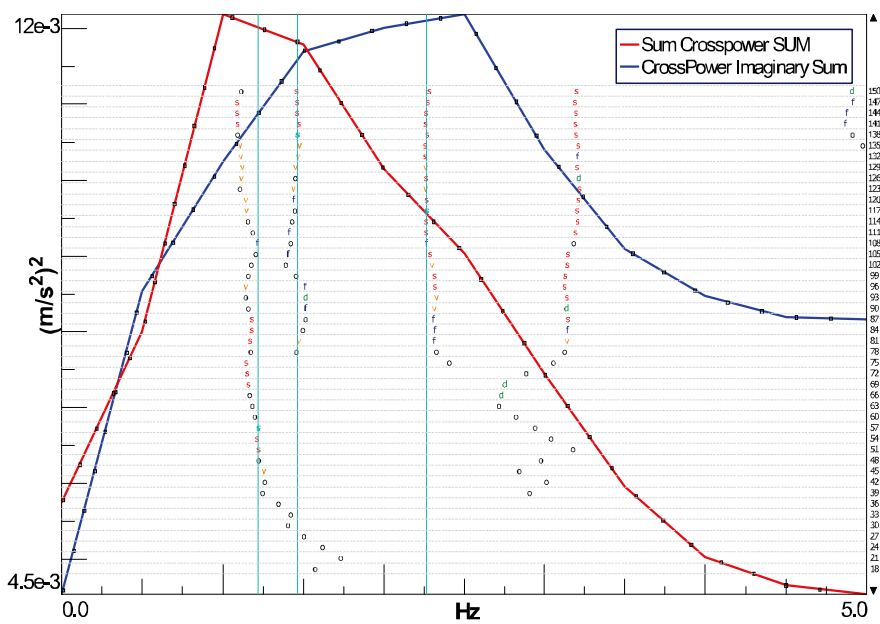

(a)

\begin{tabular}{c|c|c|c|}
$\begin{array}{c}\text { PG mode } \\
\text { Florida } \\
\text { PolyMAX }\end{array}$ & $1^{\text {st }}$ & $2^{\text {nd }}$ & $3^{\text {rd }}$ \\
\hline $\begin{array}{c}1^{\text {st }}(\text { heave }) \\
1.22 \mathrm{~Hz}, \\
31.2 \%\end{array}$ & 100 & 15,4 & 13,5 \\
\hline $\begin{array}{c}2^{\text {nd }}(\text { roll }) \\
1.46 \mathrm{~Hz}, \\
15.3 \%\end{array}$ & 15,4 & 100 & 32,5 \\
\hline $\begin{array}{c}3^{\text {rd }}(\text { pitch }) \\
2.27 \mathrm{~Hz}, \\
9.00 \%\end{array}$ & 13,5 & 32,5 & 100 \\
\hline
\end{tabular}

(b)

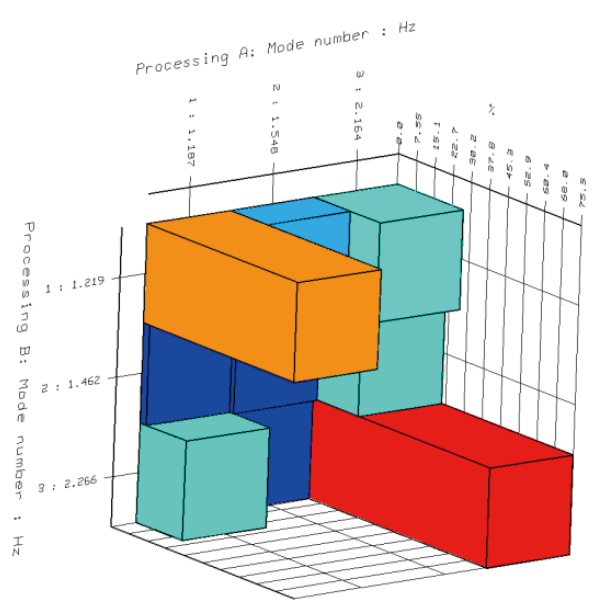

(c)

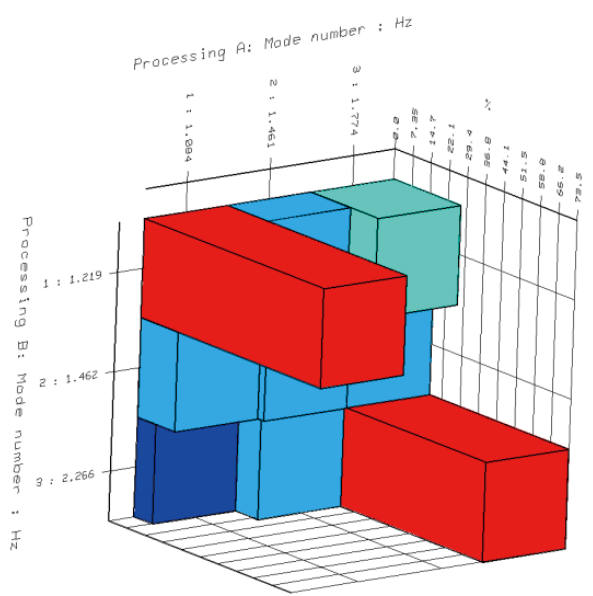

(e)

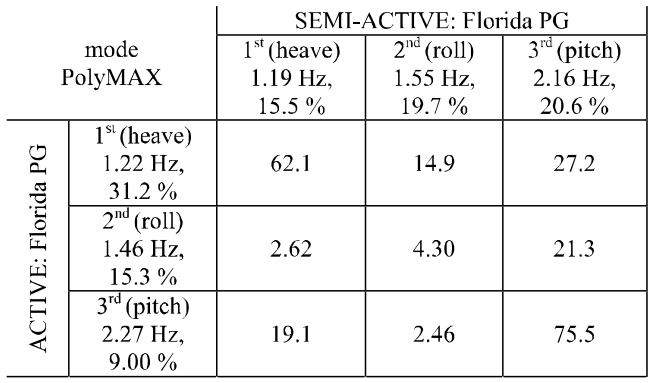

(d)

\begin{tabular}{|c|c|c|c|c|}
\hline \multirow{3}{*}{\multicolumn{2}{|c|}{$\underset{\text { PolyMAX }}{\text { mode }}$}} & \multicolumn{3}{|c|}{ SEMI-ACTIVE: Blue-Kay PG } \\
\hline & & \multirow{2}{*}{$\begin{array}{c}1^{\mathrm{st}} \text { (heave) } \\
1.08 \mathrm{~Hz} \\
7.05 \%\end{array}$} & \multirow{2}{*}{$\begin{array}{c}2^{\text {nd }}(\text { roll }) \\
1.46 \mathrm{~Hz} \text {, } \\
14.9 \%\end{array}$} & \multirow{2}{*}{$\begin{array}{c}3^{\text {rd }}(\text { pitch }) \\
1.77 \mathrm{~Hz} \\
9.07 \%\end{array}$} \\
\hline & & & & \\
\hline \multirow{5}{*}{ 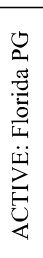 } & $1^{\mathrm{st}}$ (heave) & & & \\
\hline & $\begin{array}{c}1.22 \mathrm{~Hz} \\
31.2 \%\end{array}$ & 72.3 & 16.1 & 27.1 \\
\hline & $2^{\text {nd }}($ roll $)$ & & & \\
\hline & $\begin{array}{c}1.46 \mathrm{~Hz} \\
15.3 \%\end{array}$ & 15.0 & 17.5 & 17.3 \\
\hline & $\begin{array}{c}3^{\text {rd }}(\text { pitch }) \\
2.27 \mathrm{~Hz} \\
9.00 \%\end{array}$ & 7.49 & 16.4 & 73.5 \\
\hline
\end{tabular}

(f)

Fig. 9. Active suspension car, proving ground tests: PolyMAX stabilisation diagram and autoMAC table in the Florida case (a, b), MAC matrices and tables in the cases (c, d) active, Florida vs. semi-active, Florida and (e, f) active, Florida vs. semi-active, Blue-kay. 
Table 3

Active susp. equipped car: Comparison of the modal parameters estimated in different proving ground tests

\begin{tabular}{lccccc}
\hline \multirow{2}{*}{ PG mode } & \multicolumn{2}{c}{ Eigenfrequency [Hz] } & & \multicolumn{2}{c}{ Damping ratio [\%] } \\
\cline { 2 - 3 } \cline { 5 - 6 } PolyMAX & Blue-kay & Florida & & Blue-kay & Florida \\
\hline 1st (heave) & - & 1.22 & & - & 31.2 \\
2nd (roll) & - & 1.46 & & - & 15.3 \\
3rd (pitch) & 2.33 & 2.27 & & 10.02 & 9.00 \\
\hline
\end{tabular}

In particular, the active system operation reduces the output energy levels in the frequency range of interest ( 0 to $3 \mathrm{~Hz}$ ) for all the tests performed (Fig. 4b). As a consequence it becomes even more difficult to extract the modal parameters from the corresponding data sets. This time, indeed, only the analyses performed on the higher level Florida data sets have led to the identification of all the car rigid body modes. However, in this case, a still satisfying agreement has been obtained between four poster and proving ground tests and, for this reason, in this section, only the results of the latter test typology are reported (see Table 3 and Figs 9a and 9b where, in particular, stabilisation diagram and autoMAC had by using PolyMAX in the Florida case are shown).

Two aspects have to be stressed: (i) the estimated damping ratio of the heave mode is for this vehicle twice higher than in the previous case and (ii) the second mode shape (roll) seems to behave in a different way with respect to the other car. The correlation among them is indeed low. This can be explained recalling that on the car equipped with active suspensions, the anti-roll bar had been removed since the active system had itself the goal of counteracting the vehicle roll.

An overall comparison is finally proposed in Figs 9c and 9d, where one finds the MAC evaluated between the sets of modes identified for both the vehicles during the Florida PG test, and in Figs 9e and 9f where it is represented the MAC between the mode set identified for the active car from the Florida PG test and that identified for the semi-active one from the Blue-kay PG test.

As one can see the heave and the pitch mode are clearly identified and fine correlated, although the OMA-analysed data sets come from different vehicles during different types of proving ground tests.

\section{Conclusions}

In this paper, Operational Modal Analysis is proposed as a tool for the performance assessment of suspension systems for passenger cars. Two different suspension architectures have been, in particular, considered equipping the same model of car, a Ford S-MAX. The former is a semi-active commercial suspension system, the latter is a novel prototypic active one. Two different in-operation types of test have been performed on both the vehicles: Proving ground tests on different road profiles and laboratory tests carried out on a four poster road simulator. In the latter case, not only the same road profiles considered in the former one have been reproduced on the test rig, but also four uncorrelated white noise sequences have been utilised as input excitations. By OMA-processing the output responses acquired in the different testing conditions and by comparing the results, it is shown how this tool can be effectively utilised to verify the operation and the performance of those systems, by only carrying out simple, cost-effective road tests. In particular, the suspension operation has been analysed by OMA-estimating the modal parameters in the frequency range from 0 to $3 \mathrm{~Hz}$, which the heave, roll and pitch "rigid body" modes are expected to belong to. These modes have been actually identified for both the vehicles considered. Regarding the heave mode, in particular, the damping ratio estimated in the case of the vehicle equipped with active suspensions, has been found to be quite higher than that obtained for the other car, as expected. With regards to the quality of pole estimates, basically the same typical issues which one has to deal with when EMA-processing four poster data sets, have to be faced in the OMA case. From excitation point of view, it is useful to stress that in the case of road input, the lower are the considered frequencies, the higher is the energy level in the band of interest and, consequently, the better excited are the included modes. 


\section{Acknowledgments}

The presented research is conducted in the frame of the Flanders' Drive project InAST (Integrated Active Safety Technology) and the European Commission FP7 project MoDe ("Maintenance on Demand") coordinated by Volvo Trucks (grant agreement nr. 233890). The financial contribution from the EC is gratefully acknowledged.

\section{References}

[1] D.A. Crolla, Vehicle dynamics - Theory into practice, Proceedings of the Institution of Mechanical Engineers, Part D: Journal of Automobile Engineering 210 (1996), 83-94.

[2] R. Brincker and P. Henning Kirkegaard, Editors, Special Issue: Operational Modal Analysis, Mechanical Systems and Signal Processing 24 (2010), 1209-1323.

[3] L. Hermans and H. Van der Auweraer, Modal testing and analysis of structures under operational conditions: Industrial applications, Mechanical Systems and Signal Processing 13 (1999), 193-216.

[4] E. Guglielmino, T. Sireteanu, C.W. Stammers, G. Ghita and M. Giuclea, Semi-active Suspension Control-Improved Vehicle Ride and Road Friendliness, Springer-Verlag London Limited, 2008.

[5] H. Kowalczyk, Damper Tuning with the use of a Seven Post Shaker Rig, SAE Technical Paper Series, 2002-01-0804, 2002.

[6] S. Cafferty, K. Worden and G. Tomlinson, Characterization of automotive shock absorbers using random excitation, Proceedings of the Institution of Mechanical Engineers, Part D: Journal of Automobile Engineering 209 (1995), 239-248.

[7] D. Kowalski, M.D. Rao, J. Blough and S. Gruenberg, Dynamic testing of shock absorbers under non-sinusoidal conditions, Proceedings of the Institution of Mechanical Engineers, Part D: Journal of Automobile Engineering 216 (2002), 373-384.

[8] J. Kelly, H. Kowalczyk and H.A. Oral, Track Simulation and Vehicle Characterization with 7 Post Testing, SAE Technical Paper Series, 2002-01-3307, 2002.

[9] J. Anthonis, M. Gubitosa, S. Donders, M. Gallo, P. Mas and H. Van der Auweraer, Multi-Disciplinary Optimization of an Active Suspension System in the Vehicle Concept Design Stage, in: Recent Advances in Optimization and its Applications in Engineering 2010, M. Diehl et al., eds., Part 7, 441-450.

[10] P. Andrén, Power spectral density approximations of longitudinal road profiles, International Journal of Vehicle Design 40(2006), 2-14.

[11] S. Turkay and H. Akcay, A study of random vibration characteristics of the quarter-car model, Journal of Sound and Vibration 282 (2005), 111-124.

[12] B. Peeters, System identification and damage detection in civil engineering, $\mathrm{PhD}$ thesis, Dept. of Civil Engineering, K.U.Leuven, Belgium, 2000.

[13] B. Peeters, H. Van der Auweraer, F. Vanhollebeke and P. Guillaume, Operational modal analysis for estimating the dynamic properties of a stadium structure during a football game, Shock and Vibration 14 (2007), 283-303.

[14] A.V. Oppenheim and R.W. Schafer, Discrete-Time Signal Processing, Prentice-Hall, 1999.

[15] E. Parloo, Application of frequency-domain system identification techniques in the field of operational modal analysis, PhD thesis, Dept. of Mechanical Engineering, Vrije Universiteit Brussel, Belgium, 2003.

[16] B. Peeters and G. De Roeck, Stochastic system identification for operational modal analysis: a review, ASME Journal of Dynamic Systems, Measurement, and Control 123 (2001), 659-667.

[17] B. Peeters, H. Van der Auweraer, P. Guillaume and J. Leuridan, The PolyMAX frequency-domain method: A new standard for modal parameter estimation? Shock and Vibration 11 (2004), 395-409.

[18] H. Van der Auweraer, P. Guillaume, P. Verboven and S. Vanlanduit, Application of a fast-stabilizing frequency domain parameter estimation method, ASME Journal of Dynamic Systems, Measurement, and Control 123 (2001), 651-658.

[19] W. Heylen, S. Lammens and P. Sas, Modal Analysis Theory and Testing, K.U.Leuven, Belgium, 2007.

[20] LMS International, The LMS Theory and Background Book, Leuven, Belgium, www.Imsintl.com, 2000. 

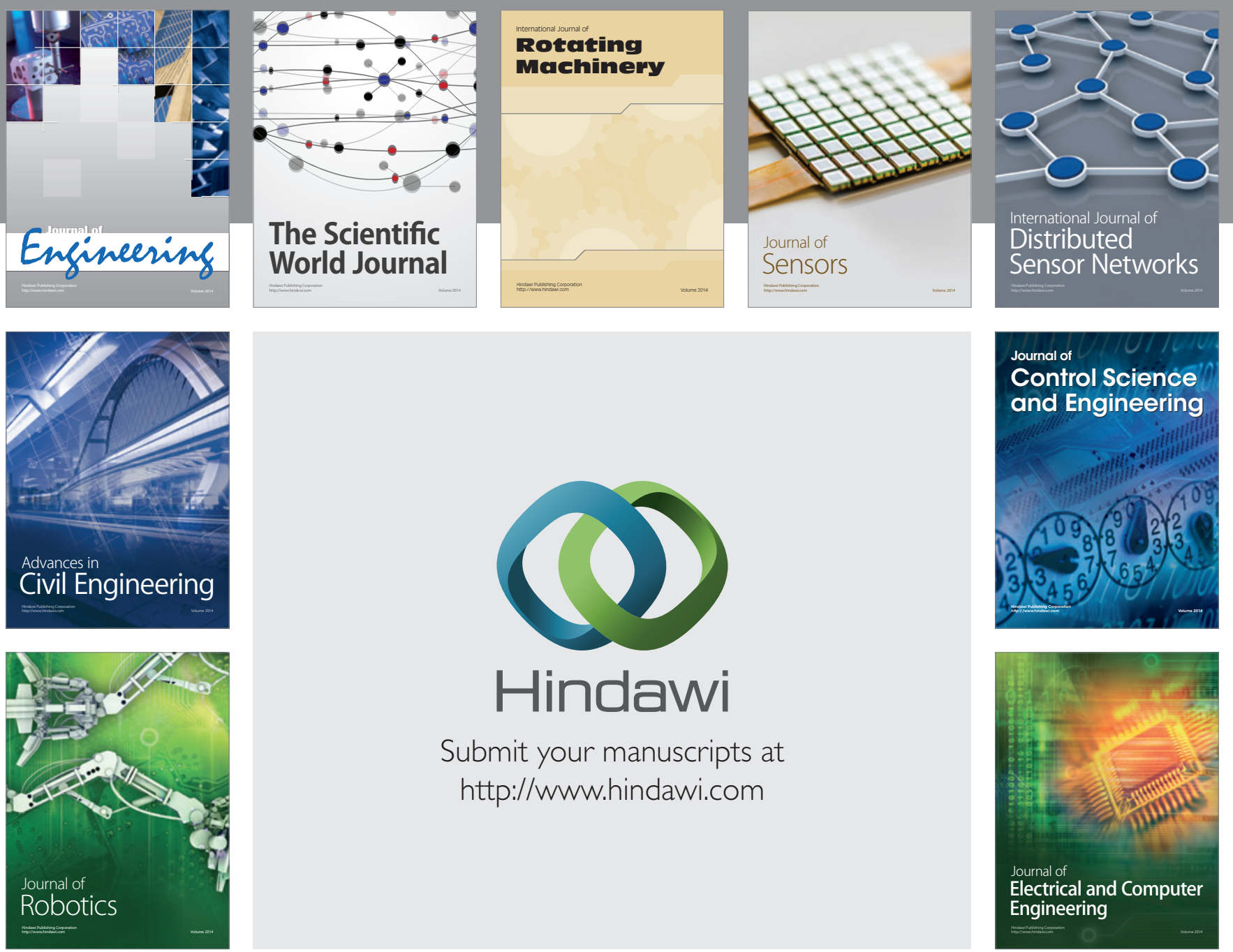

Submit your manuscripts at

http://www.hindawi.com
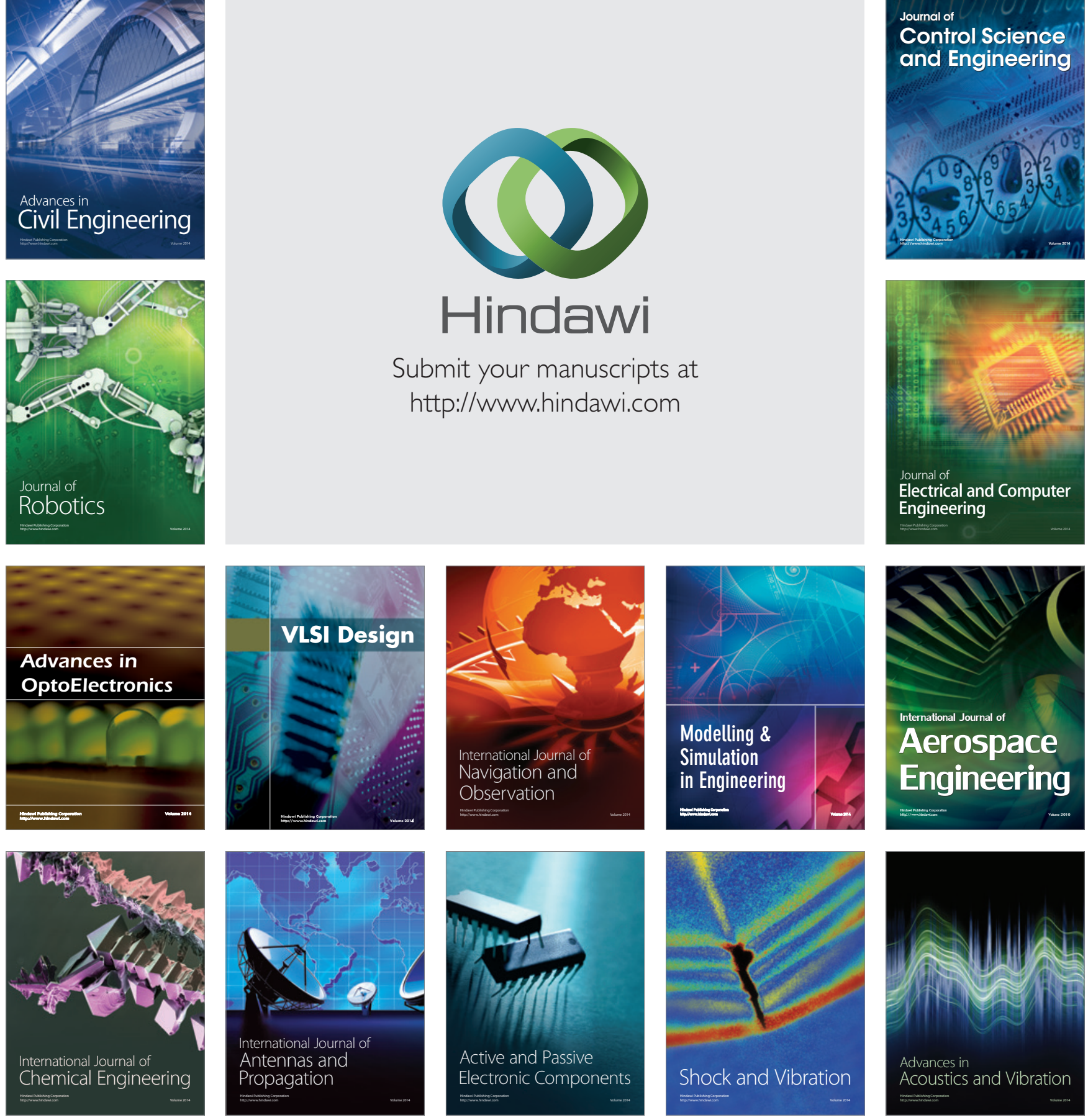